\title{
TAIWAN'S UNDERWATER CULTURAL HERITAGE DOCUMENTATION MANAGEMENT
}

\author{
Dr. Ying-Ying Tung \\ Associate Researcher, Bureau of Cultural Heritage, Ministry of Culture, 362, Sec.3 FuHsing Rd., Taichung Taiwan. R.O.C. \\ ch0235@boch.gov.tw
}

KEY WORDS: Underwater Archaeology, Site Management Plan, Records, Archives

\begin{abstract}
:
Taiwan is an important trading and maritime channels for many countries since ancient time. Numerous relics lie underwater due to weather, wars, and other factors. In the year of 2006, Bureau of Cultural Heritage (BOCH) entrusted the Underwater Archaeological Team of Academia Sinica to execute the underwater archaeological investigation projects. Currently, we verified 78 underwater targets, with 78 site of those had been recognized as shipwrecks sites. Up to date, there is a collection of 638 underwater objects from different underwater archaeological sites. Those artefacts are distributed to different institutions and museums. As very diverse management methods/systems are applied for every individual institution, underwater cultural heritage data such as survey, excavation report, research, etc. are poorly organized and disseminated for use. For better communication regarding to Taiwan's underwater cultural heritage in every level, a universal format of documentation should be established. By comparing the existing checklist used in Taiwan with guidelines that are followed in other countries, a more intact and appropriate underwater cultural heritage condition documentation system can be established and adapted in Taiwan.
\end{abstract}

\section{INTRODUCTION}

For research and understanding underwater cultural heritage it goes without saying that its context and surroundings provide important clues and indispensable information for underwater archaeology. Authenticity and context are paramount, both to heritage experience and heritage research. It is very important to emphasize complete recording information for further researcher, reuse and establish an underwater cultural heritage database.

\subsection{Underwater Cultural Heritage Act}

The Underwater Cultural Heritage Act Draft by Bureau of Cultural Heritage was deliberated by Ministry of culture, Executive Yuan, and, now, under the examination of Legislative Yuan. Meanwhile, the Underwater Cultural Heritage Regulations is being draw up as a legal instrument bounds to underwater archaeological activities.

So far, the Underwater Archaeological Team of Academia Sinica which is entrusted by Bureau of Cultural Heritage is the one operates all of the underwater cultural heritage projects in Taiwan. However, the team undertaking their procedures with relatively simple manual, with only 10 chapters and 19 items included. (Bureau of Cultural Heritage's Underwater Operation Regulations lists more detailed rules, with, in total, 6 chapters and 67items.)

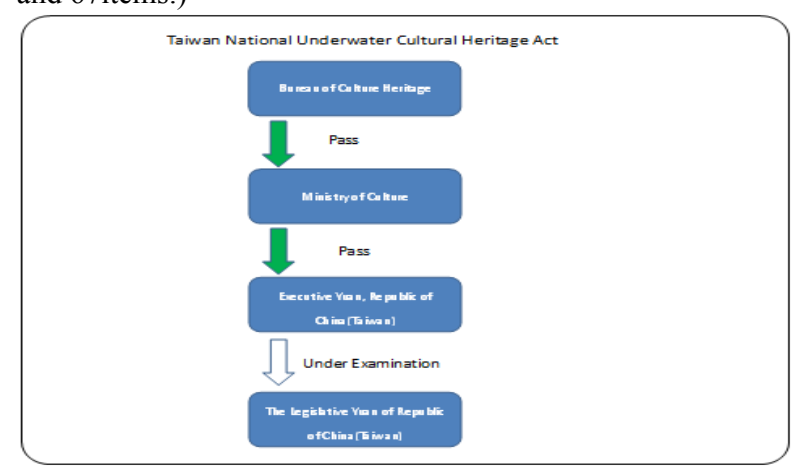

Figure 1. Legislative progress

\subsection{Underwater Cultural Heritage Affair}

Currently we do not have exclusive underwater cultural heritage certer, all the underwater archaeology administration affair are in charged by $\mathrm{BOCH}$, Different operations in a very same project like survey, excavation, research are distributed under several executive administrations' jurisdiction. The manpower is inefficiently distributed in different departments. And there is no single lead research center in charged with it. So BOCH have to pay more in collect all the results and integrate them in order to play our full authority on Taiwan's underwater archaeological operations.

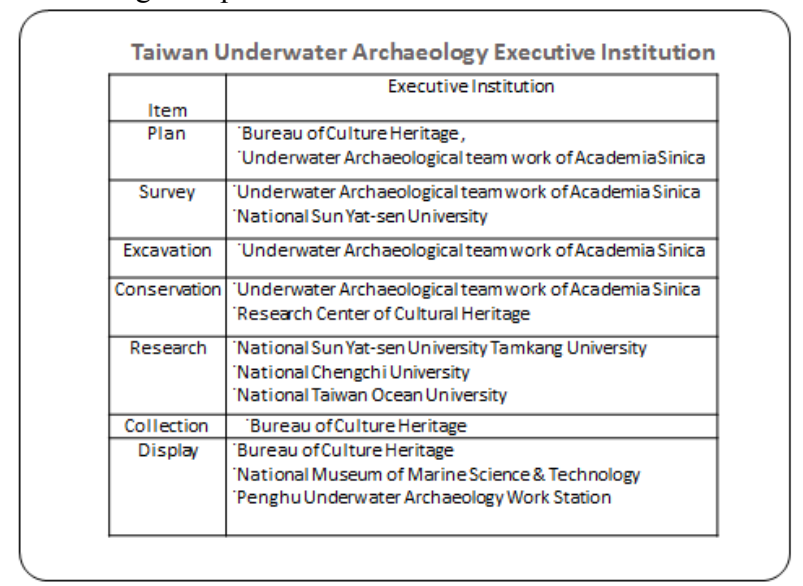

Figure 2. Taiwan underwater archaeology executive institution

\subsection{Formulating Information Management}

As we know Documentation is the cornerstone of heritage management, archaeological research, and Insufficient documentation is destruction without compensation.

Manual for activities directed at UCH???... Rule 6 : Activities directed at underwater cultural heritage shall be strictly regulated to ensure proper recording of cultural, historical and archaeological information. The competent authority should set the standards, and regulates the standards of documentation. 
For management all the results from different entrusted institution, university, $\mathrm{BOCH}$ should understand quite well underwater archaeology work procedure, the content of works and formulate all the recording sheet before entrust the works, In the end, to pay careful to examination the outcome is what BOCH important work.

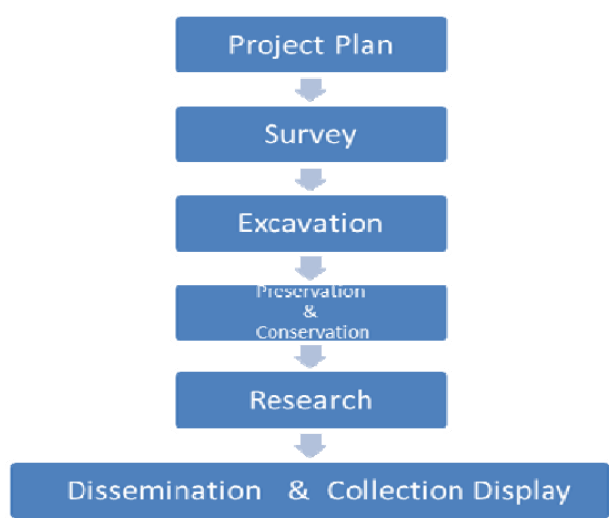

Figure 3. underwater archaeology work procedure

\subsection{Underwater Archaeology work procedure}

Different step of underwater archaeological operation have recording needs and purpose. According to the work purpose $\mathrm{BOCH}$ have to design a wide range of recording sheets. Underwater cultural heritage condition recording including information about: survey of the site, excavation, collection, recording, photographs, conservation and restoration records, etc. The record archives would not only strengthen good governance, but also protect the underwater cultural heritage, and providing information about specific area's ocean culture and evidence of human history.

\begin{tabular}{|c|c|c|}
\hline Item & Recording form & Image \\
\hline Project Design & $\begin{array}{l}\text { Plans and Section, } \\
\text { Geographical } \\
\text { Information } \\
\text { Environment Information }\end{array}$ & \multirow{5}{*}{$\begin{array}{l}\text { Literature } \\
\text { Drawings } \\
\text { Photography } \\
\text { video } \\
\text { Samples } \\
\text { Digital } \\
\text { Artefacts }\end{array}$} \\
\hline Survey & $\begin{array}{l}\text { Environmental Evidence, } \\
\text { Stratigraphy, } \\
\text { Day Books, Site Survey } \\
\text { Record }\end{array}$ & \\
\hline Excavation & $\begin{array}{l}\text { Off-Site Records, Dive } \\
\text { Record, Archaeological } \\
\text { Dive Recording, Site } \\
\text { Survey, Re-Conservation } \\
\text { Records, Probing } \\
\text { Sampling, Photographic } \\
\text { Recording Form, Video } \\
\text { Recording Form }\end{array}$ & \\
\hline Conservation & $\begin{array}{l}\text { Inventory Sheet, } \\
\text { Condition Records, } \\
\text { Treatment Records, } \\
\text { Restoration Records, } \\
\text { Initial Treatment } \\
\text { Records, Conservation } \\
\text { guide check list form. }\end{array}$ & \\
\hline Collection & $\begin{array}{l}\text { Inventory, Handling } \\
\text { Records, Keeping } \\
\text { Records }\end{array}$ & \\
\hline
\end{tabular}

Figure 4.Underwater Archaeology forms

\section{AIMS AND METHOD}

\subsection{Aims}

2.1.1 Examine Taiwan's existing underwater archaeologic recording sheets, to recognize the insufficient parts or mistreated items to revise in order to complete our recording format so that all necessary information can be collected faithfully.

2.1.2 Set lawful regulations regarding to the need to attach condition reports as indispensable appendix to project result report in the Underwater Cultural Heritage Operation Regulations.

2.1.3 Gather all of the records for proper documentation, and, at the same time, creating digitalized system for building an archaeological archive, for management and for dissemination of knowledge.

\subsection{Method}

2.2.1 Collect References UNESCO Convention, and regulations and rules of institutions and nations from: Département des Recherches Archéologiques Subaquatiques et Sous-Marines (DRASSM), Nautical Archaeology Society, Maryland Archaeological Conservation Laboratory, Jefferson Patterson Park and Museum, UNESCO Underwater Cultural Heritage Manual, Big Anchor Project, Heritage Victoria, Underwater Cultural Heritage Rules of Mainland China.

2.2.2 Comparing Compare the differences between various rules and regulations and recording forms for underwater archaeological operation.

2.2.3 Review, Recognition, and Revise Examination all the underwater Archaeology Record Sheets, finding the missing part or not perfect place to revised them in order to intact our recording form, and we could collected all the necessary information. Creating miss records, Revise not good enough parts and added the lack of parts.

Review underwater archaeology recording forms of different origins, recognize and revise the inadequate aspects of the existing recording forms used for establish intact documentation system of underwater cultural heritage in Taiwan.

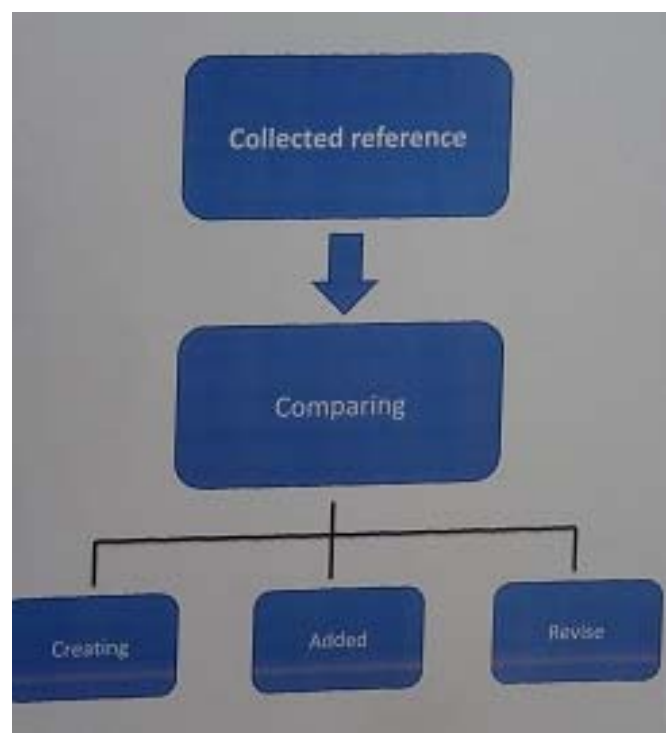




\section{Figure 5. Research Method}

\section{UNDERWATER ARCHAEOLOGY AND RECORDS}

All database begin with recording contents. For what information you want what recording form you design.

\subsection{Grand Operation}

Even for a minor underwater archaeological project, one or two vessels at minimum and a team of trained staff in different fields are required to bring the operation on going. Their work including: survey, excavation, conservation, research, and dissemination. It is a money consuming action. Every step should be operated correctly, because it is a one-time-only opportunity for every operation.

\subsection{Interdisciplinary}

Underwater archaeological operation requires involvement of different fields' specialists to cooperate. It is a team work with marine scientist marine technology professional, marine environmental researcher, detection technology specialist, marine biologist, drawer, photographer, conservator, analyst, and diver......Along with all kinds of professionals' input into the very same task; intact recording system make the operation much more manageable.

\subsection{Long-term Work}

The underwater archaeology plan always lasts for a prolonged period of time. Sometimes, they can even take several years. As the procedure on going, there will be a considerable amount of data which is needed to be organized well in order for handy usages.

\subsection{Different Personnel, Same Project}

There may be several diving teams in the project at the same time. And, most of the time, there is only one kind of format of recording is adapted for all of the staff per project. For constant recording, the record forms must be easy to understand, easy to fill in.

\subsection{The Limited Working Time Underwater}

The time human being can operate underwater for a project is limited. It depends on the time allocated to the project and the working conditions on the site. Underwater operating time might be shortened due to distinct, poor weather, adverse tidal depth conditions, size of site, temperature, visibility, experience reasons. Therefore, the recording forms should be carefully designed so that it could be efficiently done with minimum time required.

\section{UNDERWATER ARCHAEOLGY DOCUMENTATION AND MANAGEMENT}

It is very crucial to establish a underwater cultural heritage documentation system, for the sake of current study, further research, cultural heritage management, and founding underwater archaeological database. By gathering experiences from learned members of underwater archaeology field, suggestions are carried out to, hopefully, complete an intact law regarding to underwater cultural heritage regulating good practice in underwater archaeological operations.

\subsection{To establish standards recording forms}

It is important to design the recording form to avoid missing any information.

A underwater object condition report list should have the background information about the site where the object came from, Like: its origin, location found, historical period. Other essential elements such as: the project name, its reference number, the institution which object belongs to, size, environmental assessment of the excavation site, purpose of conducting the form, name and date of the form filling person, etc. Other than that, it would be more logical and efficient to arrange the checklist with situations encountered in a chronological order (from the items inspect at archaeological site to transfer, to the conservation laboratory). And item could also be put in character-related groups, so that conveniently available for all project workers to use. In addition, standard glossary must be established in all of the aspect from conducting checklist to comprehension between project worker as well as the public.

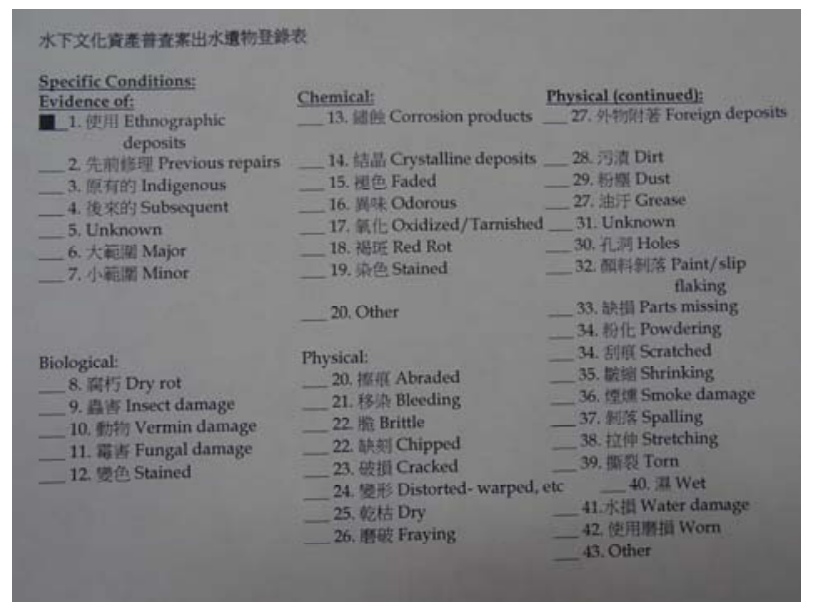

Figure 6. Case Study of the Underwater Object Condition Report.

Example:

4.1.1) 27." Foreign" body attachment could be grouped with 9., 10., 11;

4.1.2) Clear definition between 32. Paint/slip flacking and 37. Spalling should be noted.

4.1.3) Corresponding selection of terms in languages (EnglishMandarin Chinese) might cause difficulty in distinction; like: 19.Stained(染色) versus 21.Bleeding(移染).

4.1.4) Controversial translation in Mandarin Chinese; such as: 8., 10., 12., 17., 19., 21., 23.

4.1.5) The reasoning of putting 40.Wet and 41.Water damaged in the checklist.

\subsection{Information Integration}

All the information come from different institution and university or museum have to integrate the information systematic in $\mathrm{BOCH}$. Those Inter-crossing reference need a very clear Category for the database, Not just for IT personnel management is also for people looking for information more convenience in the future. The Underwater Archaeological Team of Academia Sinica's have their own database system. There are six categories: background reference, marine investigation, cultural heritage, working records, auxiliary reference, and planning reference. In fact, If we fellow the 
underwater archaeology work procedure, it is missing "excavation" category, and "working records" should depend the job type separated into each working procedure.

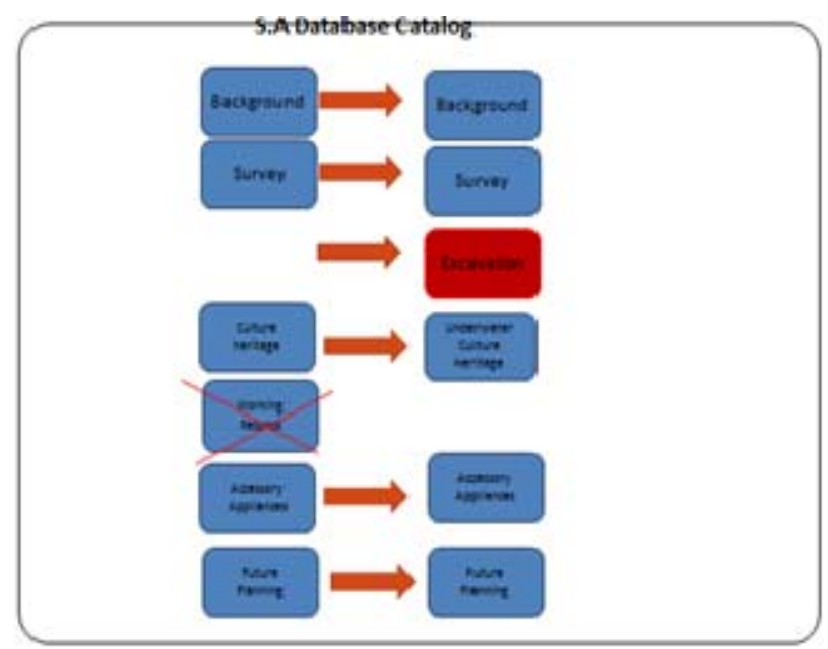

Figure 7. The database category

\subsection{Digital}

All the information from different underwater workers, may have different types, it could be by papers, drawings, photography or video. Digitized all the Information is the best way to double check whether there is any mistake, and keep all the information more safe by original and digital way.

\subsection{Dissemination}

To enhance the underwater archaeological research and promotion. It is necessary to have a underwater archaeology archive center store both the documentary archive and the material archive.

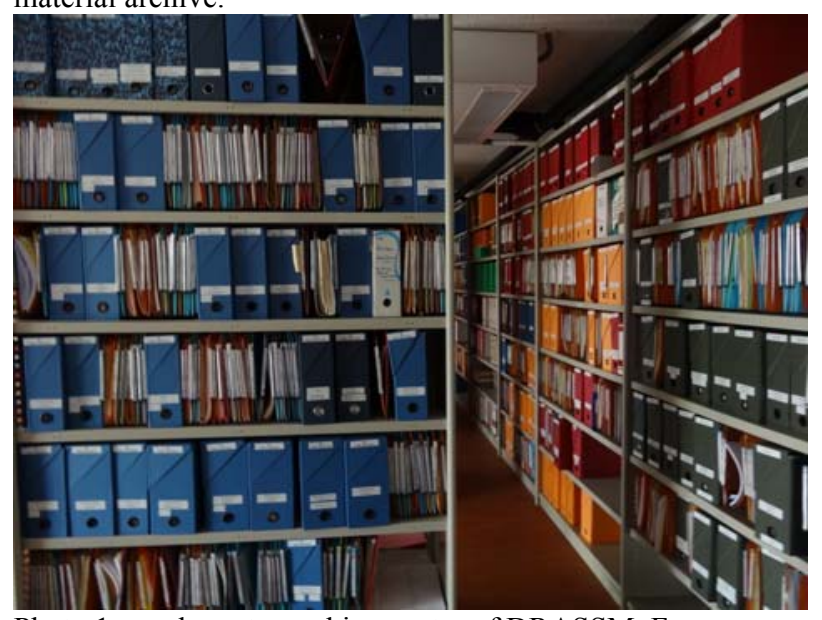

Photo 1. underwater archive center of DRASSM, France

\section{CONCLUSION}

5.1 Examining carefully the current Underwater Cultural Heritage Operation Regulations, and to adjoin extra rules in necessary to ensure all operation regarding to underwater cultural heritage is executed correctly by all.

5.2 Attaching an official, standard underwater archaeological glossary in the Underwater Cultural Heritage Operation
Regulations, to guarantee consistency and common understanding among project workers.

5.3. Establishing an exclusive underwater cultural heritage department, in the aspect of more focused management in handling underwater cultural heritage, as well as gathering specialists in related fields.

5.4. Establishing a united, complete format for use in the Underwater Cultural Heritage Operation Regulations.

5.5. Developing an underwater cultural heritage database system for disseminate knowledge.

5.6. Establishing an underwater archaeology archive in Bureau of Cultural Heritage, for better management of whole country's underwater cultural heritage possible.

5.7 Founding underwater archaeological educational programs to provide training and awareness of proper operation regulations and ethics.

\section{ACKNOWLEDGEMENTS}

Thank you for Tsai-Ti Lin M.D. and Yue-Fu Lin M.D help to Modify article and Charting.

\section{REFERENCES}

Bekić Luka., 2011. Conservation of Underwater Archaeological Finds Manual, International Centre for Underwater Archaeology in Zadar.

Donny L. Hamilton., 1987a. Methods of Conserving Archaeological Material from Underwater Sites Texas A\&M University.

Duncan H. B., 2007. Archaeological Archives, A guide to best practice in creation, compilation, transfer and curation. Institute of Field Archaeologists. UK.

Amanda B., 2009. Underwater Archaeology The NAS Guide to Principles and Practice, Blackwell, Portsmouth, UK.

Thijs J. M., 2013. Manual for Activities directed at Underwater Cultural Heritage, Guidelines to the Annex of the UNESCO 2001 Convention, Paris.

National Sun Yat-Sen University., 2012. Study of the Underwater Cultural Heritage Regulation Report: Bureau of Cultural Heritage, Taichung, Taiwan.

\section{Websites}

http://www.nauticalarchaeologysociety.org/content/proformas $(08,2015)$

http://www.unesco.org/new/en/culture/themes/underwatercultural-heritage/unesco-manual-for-activities-directed-atunderwater-cultural-heritage/unesco-

manual/documentation/documentation-programme-rules-26and-27/ (07,2015)

http://www.epa-

prema.net/documents/ressources/CIDOC2/fact2.html\#English $(05,2015)$ 
The International Archives of the Photogrammetry, Remote Sensing and Spatial Information Sciences, Volume XL-5/W7, 2015 25th International CIPA Symposium 2015, 31 August - 04 September 2015, Taipei, Taiwan

http://www.conservation-us.org/about-us/core-documents/codeof-ethics-and-guidelines-for-practice/commentaries-to-theguidelines-for-practice/24 $(08,2015)$

http://www.archaeologists.net/codes/ifa(08/2015)

www.seasearch.org.uk(07/2015)

http://www.mavic.asn.au/resources(07/2015) 